\title{
A ÉTICA DA RESPONSABILIDADE NA OBRA O SER E O NADA
}

\author{
Luciene Braga Ramos Borges ${ }^{1}$; Malcom Guimarães Rodrigues ${ }^{2}$ \\ 1. Bolsista PIBIC/CNPq, Graduanda em Licenciatura em Filosofia, Universidade Estadual de Feira de Santana, e-mail: \\ lucieneramos@hotmail.com \\ 2. Malcom Guimarães Rodrigues, Departamento de Ciências Humanas e Filosofia, Universidade Estadual de Feira de \\ Santana, e-mail: $\underline{\text { malcomgr@gmail.com }}$
}

PALAVRAS-CHAVE: liberdade; responsabilidade; Sartre

\section{INTRODUÇÃO}

Este resumo expandido tem como objetivo principal analisar a relação entre os conceitos de liberdade e responsabilidade, propostos por J-P Sartre, na obra O Ser e o Nada (2014/1943). Nesta obra, Sartre define a liberdade em termos ontológicos enquanto que a responsabilidade parece definir-se em termos morais. Se não há motivações a priori para as nossas ações, se os valores só aparecem na e depois da liberdade, então, não há um bem ou um mal que nos guia e que justifica nossas ações. Não obstante, se estas ações, praticadas por nós, são escolhidas livremente, então, devemos assumir que o mundo que elas criam, no qual tais valores aparecem, é nossa responsabilidade. Para Sartre, "a existência precede a essência" (SARTRE, 2010, p. 25), o que significa afirmar que a realidade humana não traz consigo uma definição, ou seja, ela é aquilo que faz de si ao longo de um processo histórico. Este é, segundo Sartre, o primeiro princípio do existencialismo. Então, para o autor, apesar de não haver um determinismo psicológico ou qualquer outro tipo de determinismo guiando nossas ações, precisamos assumir todas as consequências que nossas ações criam. Partindo do princípio citado, o autor considera que podemos colocar a realidade humana em posse do que é, a saber, um projeto que não encontra em si nem no mundo justificativas. Podemos atribuirlhe total responsabilidade pelos seus atos. A questão principal trabalhada na pesquisa, é, portanto, se diante destas colocações, apontadas por Sartre, podemos pensar em uma implicação ética, na O Ser e o Nada (2014/1943), a partir da reflexão ontológica sobre a liberdade.

\section{MATERIAL E MÉTODOS OU METODOLOGIA (ou equivalente)}

A metodologia da pesquisa é de natureza bibliográfica, os materiais usados são de ordem textual: livros, artigos, textos etc. A metodologia consistiu em leituras, fichamentos, análises textuais, das obras propostas, relacionadas ao tema. Os encontros com o orientador para discutir o tema e a participação no grupos de estudo e pesquisa foram fundamentais, especialmente no início, momento no qual as primeiras leituras e a trajetória da pesquisa foram discriminadas e analisadas.

\section{RESULTADOS E/OU DISCUSSÃO (ou Análise e discussão dos resultados)}

Na obra O Ser e o Nada (1943/2014a), Jean-Paul Sartre afirma que a consequência essencial das observações feitas, na sua filosofia, é que a realidade humana está condenada a ser livre e "carrega nos ombros o peso do mundo inteiro: é responsável pelo mundo e por si mesmo enquanto maneira de ser" (SARTRE, 2014a, p. 678). Afirma, ainda, que a responsabilidade absoluta é uma reinvindicação das consequências da liberdade absoluta, ou seja, o que acontece com a realidade humana é através dela que acontece. Na pesquisa descrevemos, em primeiro lugar, quais os argumentos que o autor usa para responder a questão da liberdade absoluta. Quais são as implicações na ética da responsabilidade tendo em 
vista que o questionamento é, acima de tudo, sobre o que representa, para a realidade humana, a liberdade como autonomia de escolha em relação a fatos que, em princípio, estão dados no mundo. Sartre (2014a, p.677) começa o capítulo III da quarta parte, intitulado "Liberdade e Responsabilidade", afirmando que toma o termo responsabilidade no sentido de: "consciência (de) ser o autor incontestável de um acontecimento ou de um objeto" (SARTRE, 2014a, p.678). Mesmo diante de qualquer "coeficiente de adversidade", a realidade humana é autora incontestável dos seus atos, que adquirem sentido pelo projeto assumido e reassumido por ela. É pelo comprometimento neste projeto que ela se faz e se lança em direção ao futuro. A radicalidade do pensamento sartriano está na afirmação de que não pode haver coerção frente à liberdade da realidade humana, nem mesmo em uma situação que pareça externa a ela. Sendo assim, segundo Sartre, não há "acidentes" em uma vida, uma ocorrência comum que irrompe subitamente e que carrega a realidade humana. Ele afirma que um ato realizado, por esta realidade humana, é sem desculpas "não provém de fora [...] não tenho desculpa alguma, porque, como dissemos e repetimos nesse livro o próprio da realidade humana é ser sem desculpa." (SARTRE, 2014a, p. 680). Contudo, a responsabilidade é de um tipo particular, continua Sartre (2014a, p.180), porque as ações são tomadas a partir de situações nas quais, em princípio, não se pode escolher certos aspectos, inclusive não podemos escolher sermos ou não livres - facticidade - ou não existir - contingência. ${ }^{1}$ Em outras palavras, a realidade humana não é ela mesma o fundamento de seu ser. Encontra-se sozinha, "abandonada" no mundo e sem ajuda, encontra-se comprometida. ${ }^{2}$ Assim como está condenada a ser livre, também está condenada a ser "integralmente responsável” por ela mesma. Ela é: “[...] o ser que é como ser cujo ser está em questão em seu ser" (SARTRE, 2014a, p. 681). Por isso, o autor afirma com veemência que "cada pessoa é um absoluto desfrutando de uma data absoluta e totalmente impensável em outra data" (SARTRE, 2014a, p. 680). Esta responsabilidade plena, que deveria colocar a realidade humana como "consciência orgulhosa" das suas ações, é, afirma Sartre (2014a, p. 678) "reivindicação lógica" da sua liberdade. O que o autor tenta explicar, ao longo da obra $O$ Ser e o Nada (1943/2014a), é que a realidade humana é sempre escolha diante das situações e toda escolha já é um modo de "ser-no-mundo". ${ }^{3}$ Sendo assim, ela está condenada a ser responsável pela sua presença no

\footnotetext{
${ }^{1} \mathrm{Na}$ obra Existencialismo (2013) de Jacques Colette, o autor explica que Sartre retoma o termo facticidade de Heidegger e adapta a sua filosofia existencialista. Colette (2013, p.39) afirma que a liberdade da realidade humana, descrita por Sartre, não significa que ela é, para ela mesma, seu próprio fundamento. A existência da realidade humana é contingente, ou seja, sem justificação, por isso ela se faz (o tempo inteiro) em vez de ser. Concretamente, a realidade humana é livre em situação e também não há situação a não ser porque ela é liberdade. Sendo assim, Colette (2013, p.39) afirma que contingência e facticidade é a mesma coisa para Sartre. Cf. Colette, 2013, p.39,40. Veremos sobre os conceitos facticidade e contingência no capítulo II deste trabalho, no qual destacaremos o conceito de liberdade, para Sartre.
}

${ }^{2}$ Sartre afirma que estamos abandonados no mundo não no sentido de sermos passivos, mas no sentido de sermos sozinhos e sem ajuda, comprometidos em um mundo onde somos responsáveis e não podemos fugir disto e, até quando fazemo-nos passivos, estamos agindo a partir de uma escolha, ou seja, estamos nos escolhendo; é um modo de ser como outros modos de ser-no-mundo. Cf. Sartre, 2014a, p. 680

3 Sartre usa este conceito a partir de Heidegger. Na obra Ser e Tempo (1927/2012) Heidegger (2012, p.111), descreve a relação homem/mundo como pré-teórica e mais originária, portanto, para o autor, o modo como podemos perceber o fenômeno no mundo não é como um aparecer ou acontecer de entes dentro do mundo, mas como um "conceito ontológico", um "momento constitutivo de ser-no-mundo" (HEIDEGGER, 2012, § 14, p.111), em outras palavras, o mundo, conforme Heidegger explicita, pode ser entendido como constituído por uma familiaridade de referências, que sustenta uma relação que o homem mantém com o mundo, ou seja, uma relação entre o homem e o mundo. Sartre também investiga a realidade humana e o mundo a partir da totalidade homem-no-mundo ou "ser-no-mundo". Cf. Sartre, 2014a, p.44 
mundo e, mais ainda, responsável "pelo mundo inteiro como mundo povoado" (SARTRE, 2014a, p. 681).

\section{CONSIDERAÇÕES FINAIS (ou Conclusão)}

O que Sartre deixa claro, sobre o tema da ética, já nas últimas páginas da obra $O$ Ser $O$ Nada (1943/2014a), no tópico "Perspectivas morais" é que a realidade humana é um agente moral, ela é o "ser pelo qual os valores existem" (SARTRE, 2014a, p. 764). Sartre afirma, ainda, que a "ontologia não pode formular de per si prescrições morais [...] deixa entrever todavia o que seria uma ética que assumisse suas responsabilidades em face de uma realidade humana em situação" (SARTRE, 2014a, p.763). Ele sustentava, inclusive, que seria possível, através do método correto, ou seja, a psicanálise existencial, apresentar a realidade humana o objetivo real da sua busca, e por isso, ao final da obra, discutida aqui, fez vários questionamentos acerca da liberdade, dos valores, da má-fé e também acerca da responsabilidade. ${ }^{4}$ Questionamentos que, segundo ele, só poderiam ser respondidos no campo da moral. Sartre (1999, p.127) afirmou, ainda em 1945, que a liberdade pode, em alguns aspectos, se passar por maldição, porque sendo livre não se faz o que se quer. No entanto, defende que, apesar de ter que suportar o peso de si mesmo a liberdade é a única fonte da grandeza humana. Então, no mesmo movimento que ela escolhe o seu destino, escolhe o destino de todos e o valor que quer atribuir à humanidade. Sartre não escreveu o tratado prometido sobre uma ética no final da obra $O$ Ser e o Nada, (1943/2014a), porém a "[...] A ausência de um tratado de ética não significa a ausência da ética" (LEOPOLDO E SILVA, 2010, p. 269), afirma Leopoldo e Silva no artigo "Sartre e a ética" (2010), "A preocupação ética está presente na filosofia de Sartre desde o início. Não se pode entender a sua filosofia a partir das divisões tradicionais entre as disciplinas filosóficas" (LEOPOLDO E SILVA, 2010, p. 269). Segundo Leopoldo e Silva, a conferência intitulada $O$ Existencialismo é um Humanismo (1946/2010) bem demonstrou a preocupação de Sartre a este respeito. Na conferência, ele rebateu as críticas que foram direcionadas à sua obra, encaminhou as respostas pelo lado ético e utilizou a ontologia "como condição de possibilidade de esclarecer os equívocos éticos. O maior exemplo é a vinculação entre a precedência da existência, a liberdade e a responsabilidade" (LEOPOLDO E SILVA, 2010, p. 269) em cada ato de escolha da realidade humana. Esta escolha sendo individual, nas palavras de Sartre (2010, p.49), não isenta a realidade humana do compromisso com o universal.

\section{REFERÊNCIAS}

BORNHEIM, Gerd. A. "O Existencialismo de Sartre”. Curso de Filosofia. Ed. Jorge Zahar, $3^{\text {a }}$ edição, RJ, 1989, p. 195-203

(Coleção Debates)

Sartre - Metafísica e existencialismo. Editora Perspectiva. 2a edição, São Paulo, 1984.

COX, G. Compreender Sartre. Tradução de Hélio Magri Filho. - Petrópolis: RJ: Vozes, 2007.

COLETTE, Jacques. Existencialismo. Tradução de Paulo Neves.- Porto Alegre, RS: L\&PM, 2013. (Coleção L\&PM POCKET ; v. 882)

COHEN-SOLAL, Annie. Sartre - uma biografia. Tradução de Milton Persson. - 2.ed. - Porto Alegre, RS: L\&PM, 2008.

DESCARTES, René. Regras para orientação do espírito. Tradução Maria Ermantina de Almeida Prado Galvão. - 3a . ed. - São Paulo: Editora WMF Martins Fontes, 2012. - (Clássicos WMF) . Discurso do método : Meditações; tradução Roberto Leal Ferreira. 2 ed. - São Paulo:

Martin Claret, 2008. - (Coleção obra prima de cada autor; 45)

FREUD, S. Sigmund Freud: Obras Completas. Buenos Aires: Amorrortu Editores, 1996.

\footnotetext{
${ }^{4}$ Sobre o tema da psicanálise existencial, pesquisar em O Ser e o Nada (1943/2014a), capítulo 2 - Fazer e Ter A psicanálise existencial, pp. 682-703.
} 
"O eu e o id, "autobiografia" e outros textos" (1923-1925) / Sigmund Freud; tradução Paulo César de Souza - São Paulo: Companhia das letras, 2011.

“"O Inconsciente". In: Edição Standard brasileira das obras completas de Sigmund Freud. Rio de Janeiro: Imago Editora, 1996, Vol. XIV.

GUIGOT, André. Sartre. Paris. Vrin, 2007.

HEIDEGGER, M. Ser e Tempo. Parte I - Tradução Márcia de Sá Cavalcante. $7^{a}$ Edição. Petrópolis: Editora Vozes, 1998.

Ser e Tempo. Tradução revisada e apresentação de Márcia de Sá Cavalcante Schuback. Posfácio de Emmanuel Carneiro Leão. 6.ed.- Petrópolis, RJ: Vozes; Bragança Paulista, SP: Editora Universitária São Francisco, 2012.

LAPLANCHE, J. e PONTALIS, J.B. Vocabulário de psicanálise. Tradução: Pedro Tamen. São Paulo: Martins Fontes, 2001.

LEOPOLDO \& SILVA, F. "Conhecimento e identidade histórica em Sartre". Trans/form/ação. São Paulo, 26(2), p. 43-64, 2003.

2010. "Sartre e a ética". Revista Bio\&thikos. Centro Universitário São Camilo -;4(3): p.269-273,

LÈVY, Bernard-Henri. O século de Sartre: inquérito filosófico. Rio de Janeiro: Nova Fronteira, 2001.

MÉSZÁROS, István. A obra de Sartre: busca da liberdade e desafio da História. São Paulo: Boitempo, 2012.

MOUTINHO, Luiz Damon Santos. Sartre: Existencialismo e Liberdade (Coleção Logos). São Paulo: Moderna, 1996.

PERDIGÃO, Paulo. Existência e Liberdade: uma introdução à Filosofia de Sartre. Porto Alegre, RS: LP\&M, 1995.

REYNOLDS, Jack. Existencialismo. Tradução de Caesar Souza. - Petrópolis, RJ: Vozes, 2013. (Série Pensamento Moderno).

RODRIGUES, Malcom Guimarães. Consciência e má-fé no jovem Sartre: a trajetória dos conceitos. - São Paulo: Ed. UNESP, 2010.

SARTRE, J-P. O Ser e o Nada - ensaio de ontologia fenomenológica; tradução de Paulo Perdigão. 23. Ed. - Petrópolis: RJ, Vozes, 2014.

A transcendência do ego: esboço de uma descrição fenomenológica. Tradução e notas, Sylvie Le Bon; tradução de João Batista Kreuch. - Petrópolis, RJ: Vozes, 2013. - (Coleção Textos filosóficos)

$\overline{2014 b}$

Esboço de uma Teoria das Emoções. Tradução de Paulo Neves. - Porto Alegre: L\&PM,

O imaginário. São Paulo: Ática, 1996.

. O existencialismo é um humanismo. Apresentação e notas, Arlette Elkaim-Sartre; tradução de João Batista Kreuch. - Petrópolis, RJ: Vozes, 2010. - (Coleção Textos filosóficos).

O que é a Literatura? Petrópolis, RJ: Vozes, 2015.

O que é a subjetividade? - 1. Ed. - Rio de Janeiro: Nova Fronteira, 2015.

. As Palavras. Tradução de J. Guinsburg. 2.ed. Rio de Janeiro: Nova Fronteira, 2005.

Situações I. Tradução de Rui Mário Gonçalves - Publicações Europa-América, (1947).

. "Uma ideia fundamental da fenomenologia de Husserl: a intencionalidade". Situações I.

Tradução de Rui Mário Gonçalves - Publicações Europa-América, (1947). p. 28-31

. "A liberdade cartesiana" . Situações I. Tradução de Rui Mário Gonçalves - Publicações Europa-América, (1947).

Fronteira S.A., 1983.

Diário de uma guerra estranha. Tradução: Aulyde Soares Rodrigues. Editora Nova . "Entre quatro paredes. Peça em um ato". Tradução e notas de Guilherme de Almeida.

Editor Victor Civita. Abril S.A. Cultural Industrial, São Paulo, $1^{\text {a }}$ edição - março de 1977 . «Apresentação de 'Les temps modernes' ». Les Temps Modernes. Tradução de Oto Araújo

Vale. Editora HUCITEC, São Paulo, 1999. . A náusea. Tradução Rita Braga -[ Ed. Especial]. - Rio de Janeiro: Nova Fronteira, 2011. 